\title{
Hepatitis E Virus Infection: A General Review with a Focus on Hemodialysis and Kidney Transplant Patients
}

\author{
Seyed Mohammadmehdi Hosseini-Moghaddam ${ }^{a, d} \quad$ Afagh Zarei $^{b}$ \\ Seyed Moayed Alavianc ${ }^{c}$ Mehdi Mansourib \\ a Infectious Diseases and Tropical Medicine, Urology and Nephrology Research Center, Shahid Beheshti University, \\ bUrology and Nephrology Research Center, Shahid Beheshti University, and ' Gastroenterology and Hepatology, \\ Baqiyatallah Research Center for Gastroenterology and Liver Diseases, Baqiyatallah University of Medical Sciences, \\ Tehran, Islamic Republic of Iran; ${ }^{\mathrm{d}}$ Transplant Infectious Diseases, University of Toronto, Toronto, Ont., Canada
}

\section{Key Words}

Hepatitis E virus • Transplantation • Hemodialysis •

Chronic kidney disease

\begin{abstract}
Background: Hepatitis E virus (HEV) infection is a self-limited viral disease that causes acute hepatitis epidemics in developing countries. The common route of transmission for HEV is supposedly fecal-oral. Serological evidence may be unexpectedly found in hemodialysis (HD) patients and kidney transplant recipients. Although the route of HEV transmission is not usually determined in HD subjects, this virus seems to be transmitted either directly through HD or nosocomially. In this study, we gathered the published information on HEV infection in HD patients and kidney transplant recipients. Methods: For this review, we collected the relevant articles by searching through Medline and Google Scholar from January 1980 up to September 2009. Results: Some variables including older age, low education, living in rural versus urban areas and the duration of HD seem to be risk factors for HEV infection in HD patients. Compared with non-HD subjects, HEV infection may be specifically associated with poor outcome in HD patients. Specific considerations seem to be required to prevent transmission of HEV to
\end{abstract}

HD patients. Conclusion: More extensive investigations are required to determine the disease burden of $\mathrm{HEV}$ infection in HD subjects in countries which experience outbreaks of HEV infection.

Copyright ๑ 2010 S. Karger AG, Basel

\section{Introduction}

Hepatitis E virus (HEV) is a self-limited virus transmissible via the oral-fecal route; it was first discovered in New Delhi, India, in 1955 [1]. For structure, the virus has a diameter of approximately $27-34 \mathrm{~nm}$ and is described as a nonenveloped, icosahedral single-stranded RNA virus that has a similar structure to the viruses of the Caliciviridae family [2-4]. Three open reading frames (ORFs) have been recognized for the virus: the largest ORF with 1,693 codons codes for nonstructural proteins, the second comprised of 660 codons codes for structural proteins, and the last ORF is made of 123 codons and seems to be involved in making structural proteins; however, its definite role remains unclear yet. Structurally, HEV seems to be similar to the Caliciviridae family; however, computer analysis has indicated a relationship with rubella virus, particularly for portions of ORF1 [5].

Seyed Mohammadmehdi Hosseini-Moghaddam, MD

Urology and Nephrology Research Center, No. 103

Boostan 9th St., Pasdaran Ave, PO Box 1666677951

Tehran (Islamic Republic of Iran)

E-Mail karger@karger.ch Accessible online at:

www.karger.com www.karger.com/ajn 
Table 1. Seroepidemiology of HEV infection (\%) in healthy population versus HD patients in various countries

\begin{tabular}{lllll}
\hline Authors & Country & $\begin{array}{l}\text { Anti-HEV- } \\
\text { antibody-positive } \\
\text { healthy population }\end{array}$ & $\begin{array}{l}\text { Anti-HEV- } \\
\text { antibody-positive } \\
\text { HD patients }\end{array}$ & Risk factors \\
\hline Stefanidis et al. [71] & Greece & 0.23 & 4.5 & no \\
Psichogiou et al. [27] & Greece & 2.2 & 6.4 & older age \\
Ding et al. [22] & Japan & 3 & 30 & older age \\
Lee et al. [58] & Taiwan & 8.9 & 31 & blood transfusion \\
Ayoola et al. [23] & Saudi Arabia & 0.3 & 4.8 & no \\
Mateos et al. [34] & Spain & 2.8 & 6.3 & no \\
Sylvan et al. [28] & Sweden & 5.2 & 6 & older age \\
Parana et al. [55] & Brazil & 2 & 0 & no \\
Gessoni and Manoni [46] & Italy & 2.6 & 9.3 & older age \\
Buti et al. [59] & Spain & 4 & 6 & blood transfusion \\
\hline
\end{tabular}

Although HEV was first classified as belonging to the Caliciviridae family, the most updated International Committee on Taxonomy of Viruses classification has grouped it as class IV positive-sense RNA virus assumed to belong to the 'hepatitis-E-like viruses' [6]. Phylogenetic studies have demonstrated 4 main genotypes of $1-4$, and up to 24 different subtypes, so far. The clinical relevance of the subtypes is rather poorly understood. The other issue is that genotypes 1 and 2 have been found to be restricted to humans, but genotypes 3 and 4 are common in both humans and animals. Among all 4 genotypes, type 3 has been reported as the least virulent type [7]. Nonetheless, there has recently been a report of infected patients with a genotype $3 \mathrm{HEV}$ by blood transfusion in Japan [8]. The common route of transmission is fecal-oral. Other probable modes of transmission in endemic areas include vertical transmission, blood transfusions, person-to-person contact and zoonotic transmission [1]. In general, the clinical significance of other than fecal-oral routes for HEV transmission still remains to be determined.

\section{Materials and Methods}

For this review, related articles were collected by searching through Medline from January 1980 up to September 2009. We also reviewed Google Scholar to check other manuscripts or papers in regional journals that might have not been included in Medline. The search was carried out by using several predefined combinations of the following key words and MESH terms or their equivalents: 'hemodialysis', 'dialysis' 'renal transplantation', 'kidney transplantation' in combination with 'HEV' or 'hepatitis E' and 'hepatitis E virus'.

A total of 155 related articles only in the English language were collected. Of those, 119 papers were recognized to provide minor information on HEV transmission, poor data or they were written in non-English languages. Finally, we focused on 36 manuscripts which provided data on hepatitis E in hemodialysis (HD) or renal transplantation. Additionally, we used other manuscripts for a better description of the epidemiological, diagnostic and preventive concepts. The information was retrieved by S.M.H.-M. and A.-Z. Then, the manuscripts were reviewed for data relevance by S.M.H.-M., S.M.A. and A.-Z., independently. To reach a consensus, the matter was discussed in several sessions. Although the focus of the published manuscripts was on HEV status in HD and kidney transplant patients, various clinical, epidemiological, preventive, diagnostic and therapeutic aspects were covered, too.

The comparison of HEV prevalence between HD patients and the general population is provided in table 1 . By using the preliminary data, the draft of the article was prepared by A.Z. under the predetermined subtitles. Afterwards, the intermediate report was written by S.M.H.-M. in cooperation with A.-Z. and M.-M.; the final report was drafted after several sessions of reevaluating and reassessing the data. Once the preliminary data had been checked thoroughly again, the final text was composed.

Then, by reviewing the final list of titles and abstracts, those eligible were selected. The eligibility criteria for inclusion were articles published in English, using any format, in a journal or the Cochrane library. The bibliographies of the collected full articles were studied to find relevant articles, too. The final decision to include the articles was reached by consensus. In addition, those studies relevant to HEV status in HD and kidney transplant patients, but prepared by other criteria for different search purposes, were excluded.

\section{Epidemiology}

From the epidemiological viewpoint, HEV has been a frequent cause of acute hepatitis epidemics in developing countries with substandard sanitation, especially in Asia, Africa and Latin America [9, 10]. HEV has also been 
demonstrated as the second most common cause of sporadic hepatitis in North Africa, the Middle East and Europe, too [11]. A large-scale epidemic has been reported in China between 1986 and 1988 during which over 100,000 individuals were infected in the Xinjiang region of China [12], and, more recently, larger outbreaks have been reported among refugees in the war-hit areas such as Darfur in Sudan and Chad [13]. Thus, physicians expect to receive information on HEV outbreaks in developing countries with poor sewerage systems that pose as a serious risk for disaster. The virus may cause fulminant hepatitis in pregnant women in developing countries and has a tendency toward infecting older men in the developed world $[14,15]$. Thus, the epidemiological feature of $\mathrm{HEV}$ infection is quite different in the developed and the developing countries.

The seroprevalence of HEV in HD patients seems to be dependent on the prevalence of HEV infection in the general population. Nonetheless, some serological studies have been indicative of epidemics in developed regions such as the USA, Europe and Japan $[9,10]$. There have also been reports of sporadic cases in countries limited to travelers to those parts of the world endemic for the virus infection [16-19]; nonetheless, other non-travelrelated sporadic cases have been reported, too [20]. Moreover, the existence of anti-HEV IgG in some blood donors in nonendemic countries seems to stem from another unknown virus that could create antibodies cross-reacting with HEV [21]. In view of statistics and for the prevalence rate of $\mathrm{HEV}$, it varies in different countries for instance from $1-3 \%$ among healthy adults in the USA to $4.6-6.7 \%$ in Japan [22]. So far, studies have shown a global spread of HEV infection along with substantial mortality in the developing countries [23]. In the previous reports, mortality was significantly higher in patients with considerable background illness including chronic renal failure. According to the studies, the mortality rate ranges from around $1 \%$ in the general population to up to $30 \%$ in pregnant women $[24,25]$. Consequently, viral hepatitis $\mathrm{E}$ seems to be important in terms of mortality specifically in HD patients [26].

Japanese researchers have found a relationship between the increases in IgG type anti-HEV antibody positivity with age, particularly in those patients with healthy kidneys and aged 30 years and beyond: the antibody increase was found to be higher above the age of 40 years [27]. Similarly, in a study on HD patients in Sweden, the percentage of IgG-type anti-HEV antibody positivity was shown to be $2.5 \%$ in the patients under 40 years of age and $7.4 \%$ in patients aged 40 years or older, respectively [28].
In the same way, the HEV infection rate could be demonstrated to increase with age in the liver disease patients in another study [22]. The relationship between age and HEV infection might be a repercussion of the exposure to the virus many years before. There was also a gender tendency toward females in a study in Athens, i.e. a higher prevalence of HEV infection was reported in women on HD ( $p=0.04)$ [27]. In the majority of reports on hepatitis $\mathrm{E}$ in HD patients, the seroprevalence was higher in males compared with females [8].

In general, the variety of results for the prevalence of HEV infection in the general population at various geographical locations could be attributed to the criteria for patient selection and the routes of HEV transmission. The most important factors that play significant roles in HEV transmission seem to be socioeconomic, environmental and intra-unit factors in some HD units; the latter seems to deserve further investigation [23].

The most common route of transmission for HEV is fecal-oral $[23,29]$. Other studies have pointed to the parenteral route as another important way of transmission, especially in HD patients and mostly in those with a history of blood transfusion [30]. There have also been reports of HEV infection in individuals who had received blood transfusion in endemic areas [10,31-33]. Nonetheless, parenteral transmission of HEV has rarely been reported in children, as it seems that this kind of transmission requires more than the regular amounts of blood used in transfusions for children [34]. Nevertheless, other ways of transmission such as person-to-person [31-33] and mother-to-child, though seemingly improper, have been suggested by some researchers, too $[6,35,36]$. Therefore, although the fecal-oral route seems to be the most frequent path of transmission, one cannot ignore the probability of other routes. Although it has been suggested that the fecal-oral route may not be the main pathway for HEV transmission in HD centers [8], other reports are in favor of this possibility [37].

Moreover, HEV seemingly has a variety of animal hosts including rodents in some regions of the world [38, 39]. Since there have been reports of high anti-HEV seroprevalence in individuals working with animals due to their occupation, HEV seems to use zoonotic transmission, too. The virus was able to infect pigs, which further stipulates the possibility of virus spread through crossspecies contacts. Accordingly, undercooked deer and wild boar meat has been the subject of documented reports for HEV transmission in Japan [20, 40]. Food export from HEV-endemic areas might lead to HEV infection such as an avirulent HEV strain present in Europe 
possibly due to food imports that could cause subclinical infections [41]. As a result, food seems to be an acceptable vehicle for HEV transmission. Whether or not food could play a role as a vehicle in the development of hepatitis $\mathrm{E}$ outbreaks in HD centers still remains unclear [8].

The good level of hygiene in some developed countries such as Japan seems to have extremely reduced the possibility of waterborne outbreaks. Contrary to hepatitis A virus, however, the age-related spectrum of anti-HEV in the years 1974, 1984 and 1994 has not been indicative of a reduced HEV exposure in Japan in the past 20 years [42]. This finding further demonstrates that the major transmission route for HEV is possibly different to that of hepatitis A virus; hence, although it has a low infectivity and transmissibility, HEV could not be prevented by simply improving sanitation [11]. In Iran, which is endemic for $\mathrm{HEV}$ infection with a prevalence ranging from 1.1 to $37.5 \%$ in various provinces, infection reflects dissimilar levels of sanitation in different parts of the country [43].

\section{HEV Risk Factors}

The risk factors for acquisition of viral hepatitis $\mathrm{E}$ seem to be quite similar to those of the other transmissible enteric infections. Some reports could not demonstrate the association between HEV infection and wellknown risk factors; therefore more thorough investigations seem necessary to uncover the related unrecognized risk factors in those infected individuals $[6,41]$. For instance, a number of studies could not establish a definite link even between rather serious cases such as chronic $\mathrm{HD}$ and an increased risk of exposure to $\operatorname{HEV}[6,8,10$, $27,41]$.

In a study by Saffar et al. [44], it was shown that the seroprevalence rate rises with age from $1.2 \%$ at the age of $<10$ years to $7.3 \%$ in young adults. Another study in highly endemic north India has indicated that the seropositivity for anti-HEV IgG increases from $7.2-14.2 \%$ in infants to $33.3-38 \%$ by the age of 10 years [45]. In Greece, Japan, Sweden and Italy, studies have come up with similar results. This finding has possibly been due to the limited age range in all of the studies and the focus on renal failure patients $[22,27,28,46]$. It may also reflect the improvement in sanitation and water supply that plays a key role in HEV transmission. In a study by Pourahmad et al. [47], it has been shown that patients positive for HEV antibody had gone through a longer duration of HD than those negative for HEV antibody. Another study in the north of Iran had come up with the same conclusion [48]. In a study by Alvarez-Munoz et al. [49] from Mexico, age, type of community (rural or urban) and level of education were found to be important risk factors for HEV infection. Similar findings have been reported in Iran $[6$, $29,44]$. It seems that migration of people from rural to urban areas on a large scale without proper sanitation due to improper sewerage systems has contributed to the spread of disease [50].

In a study in Turkey by Oncu et al. [51], education was found to be the only factor important in pregnant women for the prevalence of HEV infection. Nonetheless, not all studies have been in support of this notion. For instance, in a study by Mathur et al. [45], the prevalence of HEV infection was found to be lower in rural areas with a high number of uneducated people than in urban areas, and this is contradictory to the result of the study in Turkey [51].

Although the association between anti-HEV positivity and the positivity for hepatitis B (HBV) or C virus (HCV) infection markers seems to be unclear $[6,34]$, some reports have shown a positive serostatus of $\mathrm{HBV}$ and $\mathrm{HCV}$ in more than $30 \%$ of anti-HEV-positive HD patients [41]. As a result, the association between HBV or HCV acquisition and HEV transmission seems to be possible.

The association of transfusion and HEV transmission still remains highly controversial. In some reports, it has been demonstrated that the frequency of anti-HEV positivity was higher in transfusion recipients if compared with nontransfused controls [30]. In addition, Fabrizi et al. [41] showed that $33 \%$ of anti-HEV-positive HD patients had a history of recurrent transfusions. Consequently, not only transmission of HEV via non-fecal-oral routes appears to be possible, but also these routes look pretty important in specific settings such as HD centers.

For the HEV relation with other diseases, multiple studies could not establish a decisive link between HEV infection and the other viruses such as $\mathrm{HBV}$ and $\mathrm{HCV}$ $[10,29,41]$. Nonetheless, some environmental factors seem to play a role in maintaining the virus in HD patients similar to HCV infection, which suggests the assumption of a common route of transmission for both viruses. For instance, anti-HEV IgG was detected in Japan significantly in some $23.6 \%$ (21/89) of hepatitis B and in $7.9 \%(12 / 152)$ of hepatitis C patients [22]. Various studies have shown that in chronic HCV infection patients, the prevalence rate of HEV infection is higher, too [5254]. An association between the presence of HEV antibody and serological evidence of previous $\mathrm{HBV}$ or $\mathrm{HCV}$ infections has also been demonstrated [46]. Since chron- 
ic hepatitis $\mathrm{C}$ has been reported to be severer in those with HEV superinfection, watchful monitoring of such patients along with anti-HEV screening at regular intervals is suggested. In children, however, no decisive link between HCV and HEV antibodies has been found yet [21]. A number of studies that tried to establish a link between other bloodborne viruses and HEV have failed to do so $[6,27]$. As a result, although some anecdotal reports demonstrated a possible association between HEV infection and other hepatotropic viruses, this association is quite ambiguous.

\section{Epidemiological Considerations for HEV Transmission in HD Centers in Detail}

As suggested in a number of studies, HEV was found to be prevalent in HD patients, either directly by HD itself or nosocomially, pointing to other routes beyond the common fecal-oral way of transmission [55]. For instance, anti-HEV IgG antibodies were found to be positive in $0-11 \%$ of HD patients, $6-15.6 \%$ of renal transplant recipients and up to $30 \%$ of the general population in the USA, respectively $[9,10]$. Similar reports from Japan, Saudi Arabia and Greece have demonstrated a noticeable HEV seroprevalence in HD patients $[22,23,56]$. In a rather large-scale study in Japan on the sera of 1,033 urban and suburban residents in Tokyo, the prevalence rate of anti-HEV IgG was found to be significantly higher in HD patients $(18 / 60 ; 30 \%)$ and the hospital staff $(8 / 87 ; 9.2 \%)$ than the healthy general population $(p<0.01)$ [22]. Also in line with certain other studies, another report from Greece showed a higher prevalence of anti-HEV in HD patients $(9.7 \%$ of 62 patients; $\mathrm{p}<0.00005)$ compared to healthy blood donors ( $0.53 \%$ of 380$)$. IgM anti-HEV prevalence rates in those patients and healthy controls were 4.8 and $0.3 \%$, respectively [56].

In contrast, some other reports demonstrated a low level of infection in their study group of HD patients. For instance, in a study in Salvador in northern Brazil, all 392 chronically hemodialyzed patients were found to be seronegative for HEV. The findings of this report may demonstrate that the rate of exposure is negligible in some parts of the world [55]. On the other hand, the negative results could be related to either the immunosuppression caused by the renal disease, a loss of antibodies or a possible weak antibody response. Receiving frequent medical advice and spending 3 days a week in a hospital environment might have further protected HD patients and helped them keep away from a possible outbreak. None- theless, HEV transmission may be important in countries with an outbreak of viral hepatitis $E$ in their general populations. In a study in the city of Tabriz in Iran, the anti-HEV IgG prevalence was detected to be as high as $7.4 \%$ in 3 different HD units. Interestingly, the result was lower than the $9.6 \%$ prevalence rate found in a previous study based on the general population $[6,57]$.

In a study in northern Italy, the frequency of antiHEV antibody was reported to be $3 \%$ in chronic HD patients attending a single dialysis unit; this was probably related to a local infection [41]. This study demonstrated evidence in favor of HEV infection among HD patients. This finding might be related to the frequency of HEV infection in the general population. On the other hand, a study from Sweden showed that in such a non-endemic area there was evidence of HEV infection in HD patients. The findings of this study showed that the seroprevalence of anti-HEV was significantly higher in patients older than 40 years [28]. As a result, age seems to be a significant factor in the epidemiology of HEV in HD patients.

In enzymatic studies, alanine transaminase (ALT) levels were usually low in HD patients even with existing acute hepatic injury. In a case-control study, it was shown that the mean ALT level was highest within $1 \pm 3$ days from the onset of the illness and that it frequently decreased afterwards. The possible reason could be the ALT assessment after the peak elevation of these hepatic enzymes [23]. As a result, the period of the liver enzyme rise in the infected subjects seems to be quite short, and the enzymes rapidly return to normal ranges. Consequently, this phenomenon appears to cause a considerable delay in the diagnosis, and some infected HD patients may not be diagnosed even in an outbreak. Hence, physicians have to maintain a high degree of suspicion in this regard.

The frequency of HEV infection among HD patients seems to be quite different in males and females. A report from Japan on a comparison between male and female patients regarding IgG-type anti-HEV antibody positivity demonstrated that it could be detected in 21.6 and $14.3 \%$ of the male and female patients, respectively. The frequency in the latter group was similar to that of subjects with healthy kidneys $[8,22]$. As a result, in HD patients, males seem to be more susceptible to HEV infection when compared with females, although this issue still remains controversial.

The role of HEV in liver disease development has been found to be minor in a number of studies on HD patients [23]. In particular, a study carried out in Spain was unable to find any clinical evidence in those HD patients or blood donors who were positive for the anti-HEV IgG. 
This could be vindicated by the virus strain being incapable of causing a clinical disease in those infected, and this type of silent seroconversion without any clinical evidence of hepatitis $\mathrm{E}$ has been recorded in outbreaks in Pakistan and Nepal, too [34].

Interestingly, transmission of HEV in HD units has been reported to have no association with the incidence of HEV infection in the general population (table 1). By and large, the presence of HEV in HD units seems to be independent of its presence in the general population of the same community. This is probably due to differences in the epidemiological characteristics of different highrisk groups [56]. It is certainly wise to take precautions in highly endemic areas to reduce the risk of HEV infection among HD patients. So far, there have been reports of separate trends in HD units in contrast to the general population [58, 59]. As a result, although significant transmission of HEV may occur from sporadic cases or an outbreak in the community to HD centers, risk factors and epidemiological trends might be quite different.

\section{HEV Infection in Kidney Transplant Recipients}

Kidney transplant patients may increase levels of liver enzymes that are mostly due to biliary tract dysfunction, sepsis, classic hepatotropic virus-related infection and drug or other toxic causes. Therefore, one should not suspect viral hepatitis only based on increased levels of liver enzymes. In otherwise healthy kidney transplant cases, HEV could be considered as the etiological agent for hepatitis in those individuals living in endemic areas [9]. The diagnosis of viral hepatitis $E$ in renal transplant recipients is usually made using the enzyme-linked immunosorbent assay (ELISA). The seroprevalence of anti-HEV IgG antibodies has been reported to be in the range of $6-16 \%$ in renal transplant recipients in some studies [24].

Surprisingly, according to some reports, HEV could develop a chronic active hepatitis and eventually cirrhosis in solid-organ recipients [57, 60, 61]. Kamar et al. [24] demonstrated that among 241 renal allograft recipients with $14.5 \%$ of anti-HEV seroprevalence, some cases suffered from chronic liver disease. They reported that HEV infection could evolve to chronic hepatitis in nearly $60 \%$ of renal transplant patients with HEV infection in endemic areas. They confirmed the diagnosis by the presence of continuously increased hepatic enzyme levels and positive serum HEV RNA, 15 months on average (range 10-24) after the acute phase when the majority remained asymptomatic [24]. They demonstrated that chronic viral hepatitis E could be quite a silent disease similar to the chronic hepatitis caused by other hepatotropic viral agents. Consequently, clinicians should not merely look for clinical evidence to consider viral hepatitis $\mathrm{E}$.

Decreasing the numbers and doses of immunosuppressive drugs still remains the first approach to control viral hepatitis $\mathrm{E}$ in renal transplant recipients. A prolonged follow-up period might be required to assess the eventual outcome [24].

In 2008, Gerolami et al. [60] reported a renal transplant subject with chronic viral hepatitis $\mathrm{E}$ and normal serum levels of liver enzymes. Surprisingly, this patient did not develop anti-HEV antibody. This study demonstrated that a transplant patient with chronic hepatitis may have normal liver enzymes and a negative serological assay. This report also highlights the need for the application of molecular studies in suspected subjects. A longer follow-up period seems to be necessary to evaluate the outcome of HEV infection in patients who undergo organ transplantation.

\section{Diagnosis of HEV Infection in HD Patients and Renal Allograft Recipients}

The diagnosis of HEV infection in HD patients and renal allograft recipients is usually made using serological assays. The diagnosis could be made either by detecting the HEV genome in serum or stool by PCR or by serological tests detecting IgM antibodies produced against HEV [24]. In general, IgM antibodies are utilized to detect acute HEV infection in the convalescent phase of the disease. Anti-HEV IgM can be detected right before the peak of ALT activity, which usually decreases some weeks or months after ALT normalization [62]. Since rheumatoid factor IgM in serum could cause false-positive results in IgM-based tests and in order to increase the specificity of the test, a concurrent anti-HEV IgA assessment has been recommended. Currently, a rapid immunochromatographic test is available to detect IgM antibodies in acute hepatitis $\mathrm{E}$ that works on the basis of reverse-flow technology and yields results in a matter of 2-3 min [63]. Anti-HEV IgA antibody detection could be used as a supplementary means to prove the acute disease if an antiHEV IgM antibody test fails to do so [64]. It has not been determined whether anti-HEV IgA plays a major role in the detection of HEV nosocomial outbreaks or not.

For anti-HEV IgG, various studies have come up with a wide range of persistence, ranging from 6 months to 14 years $[18,60,65,66]$. Since studies have demonstrated 
that IgG antibody responses to HEV weaken or vanish altogether after the acute phase of the disease, such tests are helpful mostly in the diagnosis of acute HEV infection and not so much in epidemiological studies based on serology [23]. Nonetheless and as mentioned above, since the IgG antibody titers start to rise soon after IgM antibody in the acute phase of the infection and since they persist for a rather long period of several years in many cases [28], the disease can be traced once IgM anti-HEV antibodies or HEV RNA are not used to diagnose the disease. Nevertheless, there have been reports of falsely antibody-positive or antibody-negative patients as the distribution of IgG type anti-HEV antibody titers suggests [8]. Consequently, the IgG anti-HEV assay appears to have some shortcomings in the diagnosis of HEV infection in HD patients. Moreover, during the process of $\mathrm{HD}$, a significant level of IgG is regularly cleared.

Considering the shortcomings of the anti-HEV assay in HD patients and renal transplant recipients, a serum antigen assay and molecular techniques seem to be helpful. To detect the HEV antigen (HEVAg) in the serum directly, only a few research-based tests are available at the moment. Hence, the role of serum HEVAg for the diagnosis of viral hepatitis $\mathrm{E}$ still remains under debate. By using an HEVAg assay, researchers could establish the existence of the HEVAg in liver tissue by immunofluorescent techniques. Scientists are trying to develop rapid immunochromatographic assays for serological diagnosis, too [7]. ORF 2.1 antigen, representing the carboxyterminal 267 amino acids of the capsid protein in Western immunoblotting techniques, is widely available among diverse human HEV species, and a sensitive and highly specific enzyme immunoassay, the ELISA, allows both the detection and the quantification of the related HEV-specific IgM and IgG antibodies in the acute and convalescent phases with higher specificity and sensitivity. If this materializes, the antibody responses against the virus and the HEV infection prevalence could be determined more accurately worldwide [23]. In suspected cases of acute hepatitis E, some studies have recommended HEV RNA assessment in serum up to 1 month and in stool up to 6 weeks after the first appearance of the clinical symptoms, respectively [9]. The use of an HEVAg assay and molecular techniques for the diagnosis of acute or chronic infection in HD patients or kidney allograft recipients still remains to be determined.

On the whole, the interpretation of the seroprevalence data requires caution, particularly in low-endemicity regions where only a small number of subjects with antiHEV have a history of jaundice or of traveling to HEV- endemic regions [28]. It seems that more studies using supplementary tests are required to advance the predictive value of the anti-HEV screening tests in HD patients and renal transplant recipients. As a result, a positive anti-HEV ELISA does not confirm the diagnosis. If there is either an uncertainty in diagnosis, a single diagnosis could not be reached or acute liver disease is suspected in a patient with previously chronic liver disease, liver biopsy is found to be helpful [62].

\section{Prevention and Treatment of Hepatitis E in HD Patients and Renal Transplant Recipients}

In general, vaccination, immunoprophylaxis, better public education and acceptable levels of hygiene are known to be the main measures to control HEV infection [67]. The importance of preventive measures in HEV-endemic areas in hospitals, and in the HD units in particular, has become clear since the time of an outbreak in 1992 when HEV infection spread in a hospital from an acutely infected patient [23]. To prevent HEV infection, an HEV recombinant protein vaccine has been developed [68]. In one of the immunization projects, a large-scale placebocontrolled trial of a vaccine was demonstrated to be $96 \%$ effective in the high-risk areas [69]; however, the vaccine was unavailable to commercial use. Consequently, even if the efficacy of HEV vaccine has been demonstrated, its availability still remains a major problem. Moreover, for the use of immunoglobulins, there is scant information available concerning the value of prophylaxis in the preor postexposure period and there are no established data that could prove that the immunoglobulins actually protect against HEV infection in endemic countries [67, 70]; hence, immunoglobulins play no acceptable role for HEV prevention. Instead, improvement in personal hygiene and clean food preparation seem more prudent, e.g. travelers to endemic areas should avoid high-risk activities such as drinking suspicious HEV-infested drinking water, eating uncooked shellfish, uncooked fruits or vegetables, and meat. For the treatment of HEV infection, no specific antiviral drug has been introduced yet, and its treatment has remained supportive so far $[7,67]$.

\section{Conclusion}

Hepatitis E seems to be a viral disorder transmitted via the fecal-oral route; other modes of transmission such as transfusion and HD remain controversial. 
In order to reduce the spread of HEV infection, clean water for agricultural purposes and for vegetable growth in particular, proper garbage disposal, keeping the water pipelines free from sources of infection, also increasing the public awareness to observe water hygiene and keeping a watchful eye on HEV infection in patients with hepatitis are considered to be necessary.

The trends of HEV distribution in the general population and HD patients seem to be quite distinct. Nevertheless, further studies seem to be required to uncover various modes of HEV distribution in HD centers, especially in countries with high prevalence rates for the virus. Furthermore and in order to find out the port of entry, to control transmission and to manufacture an efficient vaccine, immunological and genetic studies of sporadic and outbreak infections seem quite vital in the future.

In summary, the following may be kept in mind.

(1) In HD patients with hepatitis E, serum levels of liver enzymes may remain in normal ranges. As a result, hepatitis $\mathrm{E}$ is usually diagnosed in HD patients with a significant delay.

(2) It has been demonstrated that viral excretion begins approximately 1 week prior to the onset of illness and persists for nearly 2 weeks. As a result, asymptomatic HD patients could be the major source of nosocomial outbreaks.
(3) Parenteral routes could potentially play a role in the transmission of HEV in hospital settings.

(4) Up to now, no approved treatment has been introduced for hepatitis E. No antiviral treatment could be used for HD patients with hepatitis E. In spite of this, $\mathrm{HD}$ is not postponed because of excretion of virus from the gastrointestinal tract.

(5) Monitoring with a high degree of suspicion for the diagnosis of HEV infection in HD centers, specifically in endemic areas, regions with poor water supplementation or during outbreaks, plays the major role in prevention.

(6) Due to oral intolerance and electrolyte imbalance, HD patients with hepatitis E usually require hospital admission. As a result, medical centers providing HD services potentially remain a setting for transmission of HEV to noninfected individuals. In these situations, proper management for primary prevention is required.

(7) Kidney transplant recipients may develop chronic hepatitis after acute viral hepatitis E. These patients may have normal liver enzymes and remain seronegative. Long-term follow-up seems to be necessary for renal allograft recipients with acute HEV infection.

\section{References}

1 Chandra V, Taneja S, Kalia M, Jameel S: Molecular biology and pathogenesis of hepatitis E virus. J Biosci 2008;33:451-464.

-2 Balayan MS, Andjaparidze AG, Savinskaya SS, Ketiladze ES, Braginsky DM, Savinov AP, Poleschuk VF: Evidence for a virus in non-A, non-B hepatitis transmitted via the fecaloral route. Intervirology 1983;20:23-31.

-3 Kane MA, Bradley DW, Shrestha SM, Maynard JE, Cook EH, Mishra RP, Joshi DD: Epidemic non-A, non-B hepatitis in Nepal. Recovery of a possible etiologic agent and transmission studies in marmosets. JAMA 1984;252:3140-3145.

4 Krawczynski K, Bradley DW: Enterically transmitted non-A, non-B hepatitis: identification of virus-associated antigen in experimentally infected cynomolgus macaques. J Infect Dis 1989;159:1042-1049.

5 Koonin EV, Gorbalenya AE, Purdy MA, Rozanov MN, Reyes GR, Bradley DW: Computer-assisted assignment of functional domains in the nonstructural polyprotein of hepatitis E virus: delineation of an additional group of positive-strand RNA plant and animal viruses. Proc Natl Acad Sci USA 1992;89:8259-8263.
6 Taremi M, Khoshbaten M, Gachkar L, Ehsani Ardakani M, Zali M: Hepatitis E virus infection in hemodialysis patients: a seroepidemiological survey in Iran. BMC Infect Dis 2005;5:36.

7 Renuka Umashanker, Sanjiv Chopra: Hepatitis E virus infection; in UpToDate (17.2); UpToDate, Inc., 2009.

$\checkmark 8$ Kikuchi K, Yoshida T, Kimata N, Sato C, Akiba T: Prevalence of hepatitis E virus infection in regular hemodialysis patients. Ther Apher Dial 2006;10:193-197.

-9 Kamar N, Mansuy JM, Esposito L, LegrandAbravanel F, Peron JM, Durand D, Rostaing L, Izopet J: Acute hepatitis and renal function impairment related to infection by hepatitis $\mathrm{E}$ virus in a renal allograft recipient. Am J Kidney Dis 2005;45:193-196.

-10 Mitsui T, Tsukamoto Y, Yamazaki C, Masuko K, Tsuda F, Takahashi M, Nishizawa T, Okamoto H: Prevalence of hepatitis E virus infection among hemodialysis patients in Japan: evidence for infection with a genotype $3 \mathrm{HEV}$ by blood transfusion. J Med Virol 2004;74:563-572.
11 Emerson SU, Purcell RH: Running like water - the omnipresence of hepatitis E. N Engl J Med 2004;351:2367-2368.

12 Zhuang H: Hepatitis E and Strategies for Its Control - Viral Hepatitis in China: Problems and Control Strategies. Basel, Karger, 1992, vol 19, p 126

13 Nicand E, Armstrong GL, Enouf V, Guthmann JP, Guerin JP, Caron M, Nizou JY, Andraghetti R: Genetic heterogeneity of hepatitis Evirus in Darfur, Sudan, and neighboring Chad. J Med Virol 2005;77:519-521.

14 Mitsui T, Tsukamoto Y, Hirose A, Suzuki S, Yamazaki C, Masuko K, Tsuda F, Endo K, Takahashi M, Okamoto H: Distinct changing profiles of hepatitis $\mathrm{A}$ and $\mathrm{E}$ virus infection among patients with acute hepatitis, patients on maintenance hemodialysis and healthy individuals in Japan. J Med Virol 2006;78:1015-1024.

15 Jia ZS, Xie YM, Yin GW, Di JR, Guo WP, Huang CX, Bai XF: Successful rescuing of a pregnant woman with severe hepatitis $\mathrm{E}$ infection and postpartum massive hemorrhage. World J Gastroenterol 2003;9:631632 . 
16 Centers for Disease Control and Prevention (CDC): Hepatitis E among US travelers, 1989-1992. MMWR Morb Mortal Wkly Rep 1993;42:1-4.

17 De Cock KM, Bradley DW, Sandford NL, Govindarajan S, Maynard JE, Redeker AG: Epidemic non-A, non-B hepatitis in patients from Pakistan. Ann Intern Med 1987;106: 227-230.

18 Dawson GJ, Mushahwar IK, Chau KH, Gitnick GL: Detection of long-lasting antibody to hepatitis E virus in a US traveller to Pakistan. Lancet 1992;340:426-427.

19 Fortier D, Treadwell TL, Koff RS: Enterically transmitted non-A, non-B hepatitis: importation from Mexico to Massachusetts. N Engl J Med 1989;320:1281-1282.

-20 Ijaz S, Arnold E, Banks M, Bendall RP, Cramp ME, Cunningham R, Dalton HR, Harrison TJ, Hill SF, Macfarlane L, Meigh RE, Shafi S, Sheppard MJ, Smithson J, Wilson MP, Teo CG: Non-travel-associated hepatitis $\mathrm{E}$ in England and Wales: demographic, clinical, and molecular epidemiological characteristics. J Infect Dis 2005;192:11661172.

-21 Montella F, Rezza G, Di Sora F, Pezzotti P, Recchia O: Association between hepatitis E virus and HIV infection in homosexual men. Lancet 1994;344:1433.

-22 Ding X, Li TC, Hayashi S, Masaki N, Tran TH, Hirano M, Yamaguchi M, Usui M, Takeda N, Abe K: Present state of hepatitis E virus epidemiology in Tokyo, Japan. Hepatol Res 2003;27:169-173.

-23 Ayoola EA, Want MA, Gadour MO, Al-Hazmi MH, Hamza MK: Hepatitis E virus infection in haemodialysis patients: a case-control study in Saudi Arabia. J Med Virol 2002; 66:329-334.

24 Kamar N, Selves J, Mansuy JM, Ouezzani L, Peron JM, Guitard J, Cointault O, Esposito L, Abravanel F, Danjoux M, Durand D, Vinel JP, Izopet J, Rostaing L: Hepatitis E virus and chronic hepatitis in organ-transplant recipients. N Engl J Med 2008;358:811-817.

25 Atabek ME, Fyndyk D, Gulyuz A, Erkul I: Prevalence of anti-HAV and anti-HEV antibodies in Konya, Turkey. Health Policy 2004; 67:265-269.

26 Arinsoy T, Yilmaz M, Derici U, Sindel S, Tekin I, Hasanoglu E: Prevalence of hepatitis E virus antibody in hemodialysis patients. Nephron 1998;80:85.

27 Psichogiou M, Vaindirli E, Tzala E, Voudiclari S, Boletis J, Vosnidis G, Moutafis S, Skoutelis G, Hadjiconstantinou V, Troonen $\mathrm{H}$, Hatzakis A: Hepatitis E virus (HEV) infection in haemodialysis patients: the multicentre haemodialysis cohort study on viral hepatitis. Nephrol Dial Transplant 1996;11: 1093-1095.

28 Sylvan SP, Jacobson SH, Christenson B: Prevalence of antibodies to hepatitis E virus among hemodialysis patients in Sweden. J Med Virol 1998;54:38-43.
29 Kheradpezhouh M, Taremi M, Gachkar L, Aghabozorgi S, Khoshbaten M: Presence and significance of transfusion-transmitted virus infection in Iranian patients on maintenance hemodialysis. J Microbiol Immunol Infect 2007;40:106-111.

30 Mannucci PM, Gringeri A, Santagostino E, Romano L, Zanetti A: Low risk of transmission of hepatitis E virus by large-pool coagulation factor concentrates. Lancet 1994;343: 597-598.

- 31 Arankalle VA, Chobe LP: Retrospective analysis of blood transfusion recipients: evidence for post-transfusion hepatitis E. Vox Sang 2000;79:72-74.

32 Matsubayashi K, Nagaoka Y, Sakata H, Sato S, Fukai K, Kato T, Takahashi K, Mishiro S, Imai M, Takeda N, Ikeda H: Transfusiontransmitted hepatitis E caused by apparently indigenous hepatitis $\mathrm{E}$ virus strain in Hokkaido, Japan. Transfusion 2004;44:934-940.

33 Khuroo MS, Kamili S, Yattoo GN: Hepatitis Evirusinfection may be transmitted through blood transfusions in an endemic area. J Gastroenterol Hepatol 2004;19:778-784.

34 Mateos ML, Camarero C, Lasa E, Teruel JL, Mir N, Baquero F: Hepatitis E virus: relevance in blood donors and risk groups. Vox Sang 1999;76:78-80.

35 Karetnyi YV, Gilchrist MJ, Naides SJ: Hepatitis $\mathrm{E}$ virus infection prevalence among selected populations in Iowa. J Clin Virol 1999; 14:51-55.

36 Curry JA, Adams N, Crum-Cianflone NF: Acute hepatitis e virus infection in an HIVinfected person in the United States. Ann Intern Med 2009;150:226-227.

37 Halfon P, Ouzan D, Chanas M, Khiri H, Feryn JM, Mangin L, Masseyef MF, Salvadori JM: High prevalence of hepatitis E virus antibody in haemodialysis patients. Lancet 1994;344:746.

38 Banks M, Bendall R, Grierson S, Heath G, Mitchell J, Dalton H: Human and porcine hepatitis E virus strains, United Kingdom. Emerg Infect Dis 2004;10:953-955.

39 Meng XJ, Wiseman B, Elvinger F, Guenette DK, Toth TE, Engle RE, Emerson SU, Purcell RH: Prevalence of antibodies to hepatitis $\mathrm{E}$ virus in veterinarians working with swine and in normal blood donors in the United States and other countries. J Clin Microbiol 2002;40:117-122.

40 Arankalle VA, Chobe LP, Joshi MV, Chadha MS, Kundu B, Walimbe AM: Human and swine hepatitis $\mathrm{E}$ viruses from western India belong to different genotypes. J Hepatol 2002;36:417-425.

41 Fabrizi F, Lunghi G, Bacchini G, Corti M, Pagano A, Locatelli F: Hepatitis E virus infection in haemodialysis patients: a seroepidemiological survey. Nephrol Dial Transplant 1997;12:133-136.
42 Tanaka E, Matsumoto A, Takeda N, Li TC, Umemura T, Yoshizawa K, Miyakawa Y, Miyamura T, Kiyosawa K: Age-specific antibody to hepatitis $\mathrm{E}$ virus has remained constant during the past 20 years in Japan. J Viral Hepat 2005;12:439-442.

43 Ghorbani G, Alavian S, Esfahani A, Assari S: Seroepidemiology of hepatitis E virus in Iranian soldiers. Hepatitis Monthly 2007; 7: 123-126.

-44 Saffar MJ, Farhadi R, Ajami A, Khalilian AR, Babamahmodi F, Saffar H: Seroepidemiology of hepatitis E virus infection in 2-25-yearolds in Sari district, Islamic Republic of Iran. East Mediterr Health J 2009;15:136-142.

45 Mathur P, Arora NK, Panda SK, Kapoor SK, Jailkhani BL, Irshad M: Sero-epidemiology of hepatitis E virus (HEV) in urban and rural children of North India. Indian Pediatr 2001; 38:461-475.

46 Gessoni G, Manoni F: Hepatitis E virus infection in north-east Italy: serological study in the open population and groups at risk. J Viral Hepat 1996;3:197-202.

47 Pourahmad M, Sotoodeh A, Nasiri H: Hepatitis $\mathrm{E}$ virus infection in hemodialysis patients: a seroepidemiological survey in Jahrom, Southern Iran. Hepat Mon 2009;9: 232-235.

-48 Ansar MM, Kooloobandi A: Prevalence of hepatitis $C$ virus infection in thalassemia and haemodialysis patients in North Iran Rasht. J Viral Hepat 2002;9:390-392.

49 Alvarez-Munoz MT, Torres J, Damasio L, Gomez A, Tapia-Conyer R, Munoz O: Seroepidemiology of hepatitis $\mathrm{E}$ virus infection in Mexican subjects 1 to 29 years of age. Arch Med Res 1999;30:251-254.

50 Tarrago D, Lopez-Velez R, Turrientes C, Baquero F, Mateos ML: Prevalence of hepatitis $\mathrm{E}$ antibodies in immigrants from developing countries. Eur J Clin Microbiol Infect Dis 2000;19:309-311.

51 Oncu S, Oncu S, Okyay P, Ertug S, Sakarya S: Prevalence and risk factors for HEV infection in pregnant women. Med Sci Monit 2006;12:CR36-CR39.

-52 Pisanti FA, Coppola A, Galli C: Association between hepatitis $\mathrm{C}$ and hepatitis $\mathrm{E}$ viruses in southern Italy. Lancet 1994;344:746-747.

-53 Psichogiou MA, Tassopoulos NC, Papatheodoridis GV, Tzala E, Klarmann R, Witteler H, Schlauder GG, Troonen H, Hatzakis A: Hepatitis $\mathrm{E}$ virus infection in a cohort of patients with acute non-A, non-B hepatitis. J Hepatol 1995;23:668-673.

54 Bayram A, Eksi F, Mehli M, Sozen E: Prevalence of hepatitis $\mathrm{E}$ virus antibodies in patients with chronic hepatitis $\mathrm{B}$ and chronic hepatitis C. Intervirology 2007;50:281-286.

55 Parana R, Cotrim HP, Cortey-Boennec ML, Trepo C, Lyra L: Prevalence of hepatitis E virus IgG antibodies in patients from a referral unit of liver diseases in Salvador, Bahia, Brazil. Am J Trop Med Hyg 1997;57:60-61. 
-56 Dalekos GN, Zervou E, Elisaf M, Germanos N, Galanakis E, Bourantas K, Siamopoulos $\mathrm{KC}$, Tsianos EV: Antibodies to hepatitis E virus among several populations in Greece: increased prevalence in an hemodialysis unit. Transfusion 1998;38:589-595.

-57 Kamar N, Mansuy JM, Cointault O, Selves J, Abravanel F, Danjoux M, Otal P, Esposito L, Durand D, Izopet J, Rostaing L: Hepatitis E virus-related cirrhosis in kidney- and kidney-pancreas-transplant recipients. Am J Transplant 2008;8:1744-1748.

$\checkmark 58$ Lee CC, Shih YL, Laio CS, Lin SM, Huang MM, Chen CJ, Chen CP, Chang CL, Chen LR, Tschen SY, Wang CH: Prevalence of antibody to hepatitis E virus among haemodialysis patients in Taiwan: possible infection by blood transfusion. Nephron Clin Pract 2005;99:c122-c127.

-59 Buti M, Jardi R, Cotrina M, Rodriguez-Frias F, Troonen H, Viladomiu L, Esteban JI, Esteban R, Guardia J: Hepatitis E virus infection in acute hepatitis in Spain. J Virol Methods 1995;55:49-54.

60 Gerolami R, Moal V, Colson P: Chronic hepatitis $\mathrm{E}$ with cirrhosis in a kidney-transplant recipient. N Engl J Med 2008;358:859-860.
61 Haagsma EB, van den Berg AP, Porte RJ, Benne CA, Vennema H, Reimerink JH, Koopmans MP: Chronic hepatitis E virus infection in liver transplant recipients. Liver Transpl 2008;14:547-553.

62 Woofter A, Sussman N: Jaundice in a traveler returning from India. Med Gen Med 2006;8:48.

63 Chen HY, Lu Y, Howard T, Anderson D, Fong PY, Hu WP, Chia CP, Guan M: Comparison of a new immunochromatographic test to enzyme-linked immunosorbent assay for rapid detection of immunoglobulin $\mathrm{M}$ antibodies to hepatitis E virus in human sera Clin Diagn Lab Immunol 2005;12:593-598.

64 Zhang S, Tian D, Zhang Z, Xiong J, Yuan Q, Ge S, Zhang J, Xia N: Clinical significance of anti-HEV IgA in diagnosis of acute genotype 4 hepatitis E virus infection negative for antiHEV IgM. Dig Dis Sci 2009;54:2512-2518.

65 Khuroo MS, Kamili S, Jameel S: Vertical transmission of hepatitis $\mathrm{E}$ virus. Lancet 1995;345:1025-1026.

66 Centers for Disease Control (CDC): Enterically transmitted non-A, non-B hepatitis east Africa. MMWR Morb Mortal Wkly Rep 1987;36:241-244.

67 Mushahwar IK: Hepatitis E virus: molecular virology, clinical features, diagnosis, transmission, epidemiology, and prevention. J Med Virol 2008;80:646-658.
68 Shrestha MP, Scott RM, Joshi DM, Mammen MP Jr, Thapa GB, Thapa N, Myint KS, Fourneau M, Kuschner RA, Shrestha SK, David MP, Seriwatana J, Vaughn DW, Safary A, Endy TP, Innis BL: Safety and efficacy of a recombinant hepatitis E vaccine. $\mathrm{N}$ Engl J Med 2007;356:895-903.

69 Zhou YX, Lee MY, Ng JM, Chye ML, Yip WK, Zee SY, Lam E: A truncated hepatitis E virus ORF2 protein expressed in tobacco plastids is immunogenic in mice. World J Gastroenterol 2006;12:306-312.

70 Zhang M, Emerson SU, Nguyen H, Engle R, Govindarajan S, Blackwelder WC, Gerin J, Purcell RH: Recombinant vaccine against hepatitis E: duration of protective immunity in rhesus macaques. Vaccine 2002;20:32853291.

71 Stefanidis I, Zervou EK, Rizos C, Syrganis C, Patsidis E, Kyriakopoulos G, Sdrakas L, Tsianas N, Rigopoulou EI, Liakopoulos V, Dalekos GN: Hepatitis E virus antibodies in hemodialysis patients: an epidemiological survey in central Greece. Int J Artif Organs 2004;27:842-847. 